\title{
CO-OPERATING EXPERT KNOWLEDGE AND ARTIFICIAL NEURAL NETWORKS FOR FAULT DIAGNOSIS OF ELECTROHYDRAULIC CYLINDER POSITION CONTROL SYSTEMS
}

\author{
J WATTON and J C STEWART \\ School of Engineering \\ University of Wales, Cardiff \\ UK
}

\begin{abstract}
Results are presented from a study of leakage losses from a position control system and the resulting knowledge that may be incorporated into an on-line expert system for fault diagnosis. The use of a minimum number of sensors results in leakage and position error data that have limitations for multiple-fault situations. It is then shown how the application of an artificial neural network can give additional confidence to a fault assertion, and results are shown for a number of leakage conditions.
\end{abstract}

\section{KEY WORDS}

Fault diagnosis, Artificial intelligence, Electrohydraulics

\section{INTRODUCTION}

Fault diagnosis of fluid power systems is receiving a growing interest by industry, particularly in large manufacturing plant, as experienced by the authors. In this respect research and development at Cardiff has concentrated on leakage detection due to its immediate impact on both machinery down-time and environmental issues. An approach is required that can handle potentially a large amount of data, on-line, and from a range of sensors typically pressure, flow rate, temperature and position. In addition, fault diagnosis is often required to be component specific, or at the very least subsystem-specific. This inevitably requires sensors to be placed within the appropriate fluid power circuit and often not in the ideal place due to operating constraints, particularly vibration and temperature in heavy process industries. Large knowledge bases are therefore rapidly acquired for even the most simple of circuits, and some examples may be found in earlier work by the authors which has considered both motor and cylinder drives
[1,2,3]. The open-loop cylinder drive with flow metering discussed in [3] particularly highlights knowledge base complexity where using an expert system approach to identify 10 different types of fault in lines, actuator, and a flow control valve. An alternative approach is to use Failure Modes and Effects Analysis, whereby primitive relations between quantities, smaller than, greater than, etc., are used to deduce the effect on other component characteristics within the system $[4,5]$. This is still a complex operation, particularly for multiple faults, and it has been established that qualitative reasoning algorithms are not suitable for FMEA, although they may have a role in fault diagnosis [6]. It is then proposed that systems simulation, particularly for steady-state conditions, may be utilised in an automated FMEA approach. Artificial Neural Networks are showing promise for describing the behaviour of hydraulic circuit components and also for fault classification $[7,8,9]$. An advantage is that network training is 
undertaken using real data, admittedly for the appropriate fault conditions, although experience is also suggesting that a knowledge of system dynamics is useful in establishing the network topology.

Continuing work by the authors, and being discussed here, is concerned with closed-loop position control of a loaded hydraulic cylinder, and appropriate leakage faults are first assessed via an expert system approach. Additional information on position error is then considered, together with a fault assessment using a trained artificial neural network to support the conclusions obtained from the expert system approach.

\section{KNOWLEDGE ACQUISITION}

Previous work [2,3] has shown how an expert system shell may be utilised to on-line diagnose leakages on an open-loop cylinder drive incorporating a directional control valve. In this study a servovalve is used for conventional closed-loop position control of a cylinder with a force-dominant load as shown in Fig.1.

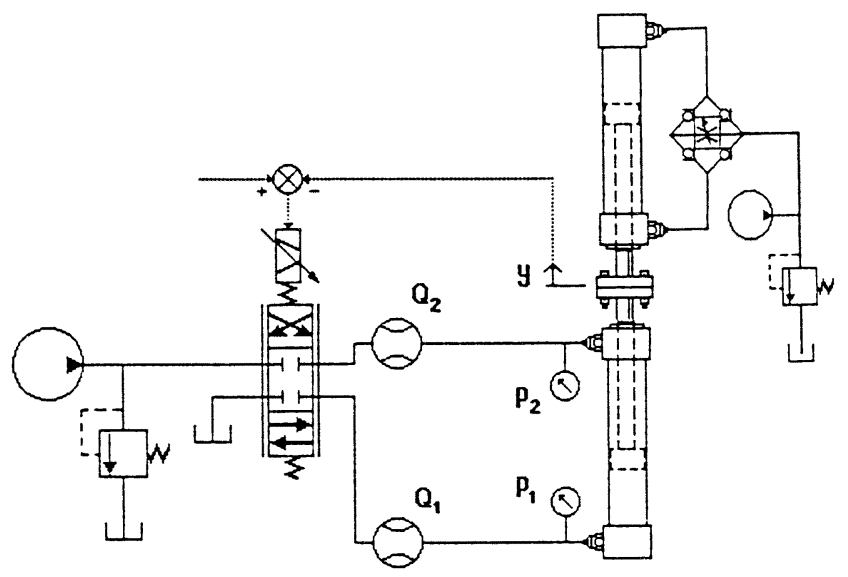

Fig.1 Hydraulic circuit diagram of the test rig

Two flow meters were placed adjacent to the servovalve output ports and the electrical signals together with those from each pressure transducer, cylinder position, and the control error signal were connected via a data acquisition card to a microcomputer incorporating an expert system software package. In addition the control signal was generated by the microcomputer such that a completely automated fault diagnostic system could be developed. In the context of leakage flow detection, i.e. from both lines and across the cylinder piston seal, knowledge may be acquired from the following sources:

i) step response dynamics

ii) displaced volumes during step response test

iii) steady-state position error

iv) steady-state characteristics utilising flow rates.
The first approach utilising the transient response to a step input is of little value for a cylinder drive with negligible inertia effects as in this case. The response is a first-order characteristic which undergoes a negligible change when faults are introduced. Hence time series analysis techniques do not produce significant changes in coefficients to be used for diagnostic purposes. The displaced volume concept first developed in $[2,3]$ is a powerful approach to leakage detection whereby the flow continuity equations for the cylinder, combined with a derived third equation, are transformed to a set of rules embedded within an expert system.

The first control action was therefore to initiate a step change in position of typically $20 \mathrm{~mm}$ and take 30,000 samples of two flow rates, two pressures and one position transducer. This procedure occurred in two seconds, and both extending and retracting steps were used. Displaced volumes are calculated from flow rate integration, these being $V_{1}$ and $V_{2}$ from flow meter 1 and flow meter 2 . The theoretical displaced volumes $A_{1} S$ and $A_{2} S$ are known, where $A_{1}$ and $A_{2}$ are the cylinder cross-sectional areas and $\mathrm{s}$ is the known stroke change. A truth table for extending only will then appear as shown in Table 1.

Support for the single-fault classification case may be obtained from consideration of the steady-state position errors which must exist in the presence of leakage. More specifically, unique combinations of position error when extending and retracting may be obtained when the load force is above a value to ensure that the pressure differential changes sign for the two cases. In the present system this occurred for a load pressure of $60 \mathrm{bar}$, and some measurements are shown in Fig. 2 for both extending and retracting cases. From Fig. 2 it is deduced that unique error trends exist for developing simple faults, the increasing or decreasing trends being indicated in Table 2.

It will also be seen from Fig 2 that a tolerance band of $10 \mathrm{mV}(0.23 \mathrm{~mm})$ is introduced to allow for the practical variation in the error characteristics due to temperature effects and servovalve spool underlap effects.

\section{THE INTEGRATION OF ARTIFICIAL NEURAL NETWORKS FOR FAULT CLASSIFICATION}

An MLP network was trained for a range of leakage flow single fault and multiple fault conditions. This was achieved again by direct computer control by demanding a constant actuator velocity over the full stroke and in both directions. Actuator position was found to have little advantage as training data and hence four inputs were used, two flow rates and two pressures. One hidden layer with 6 neurons only was 


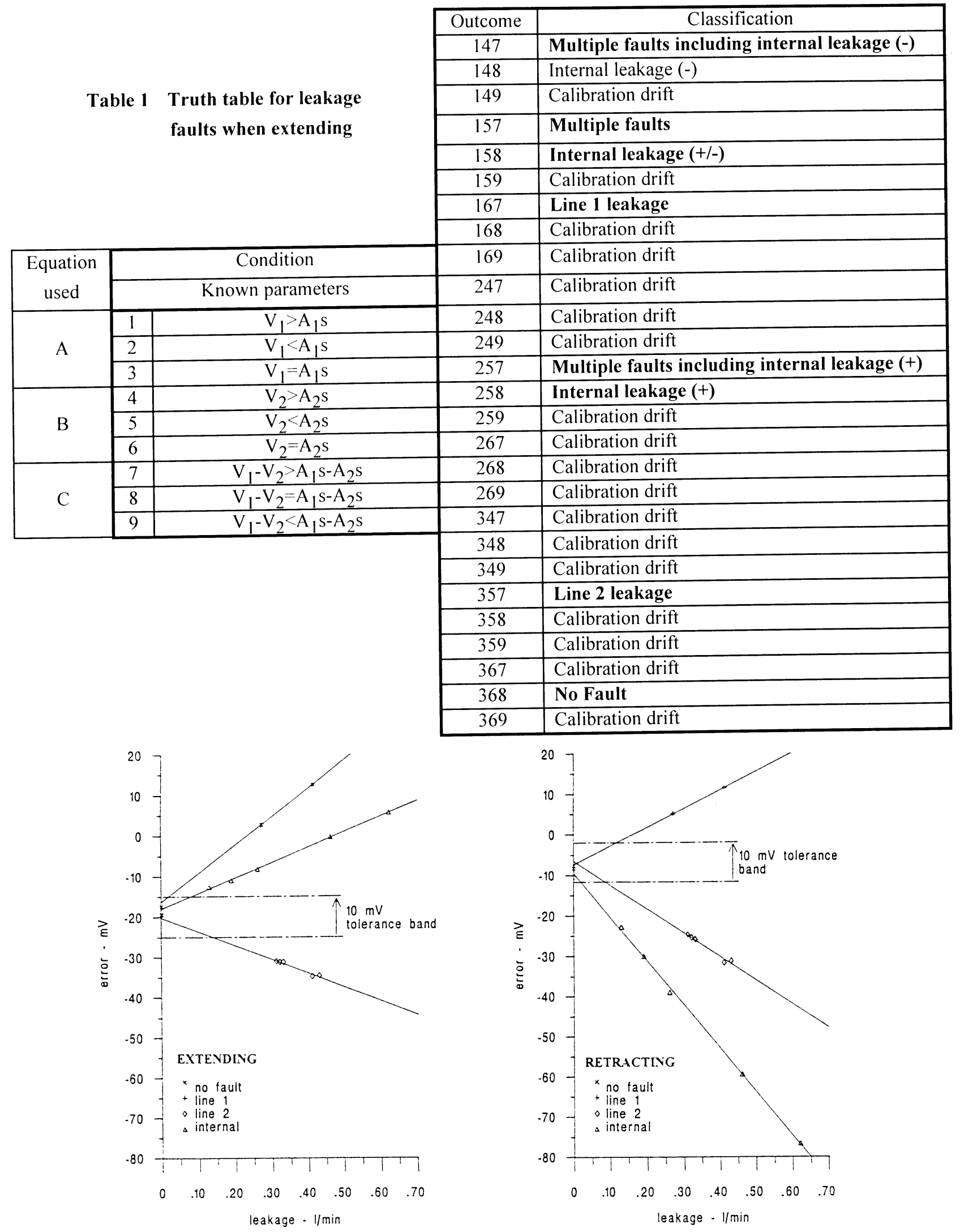

Fig.2 Position errors for different single-leakage conditions 
found to be adequate and the output layer had 3 neurons having states of either 0 or 1 to indicate no fault or fault respecively. Leakage flow rates used for training were typically between $0.5-1.0 \mathrm{l} / \mathrm{min}$, and fault detection rates were extremely high for the higher flow rates. A summary of the network performance is given in Table 3.

Table 2 Error trends for single fault conditions

\begin{tabular}{|c|c|c|}
\cline { 2 - 3 } \multicolumn{1}{c|}{} & \multicolumn{2}{c|}{ Error $(0.023 \mathrm{~mm} / \mathrm{mV})$} \\
\hline Fault & Extending $\mathrm{mV}$ & Retracting $\mathrm{mV}$ \\
\hline none & $-17 \rightarrow-20$ & $-7 \rightarrow-11$ \\
line 1 & increase & increase \\
line 2 & decrease & decrease \\
internal & increase & decrease \\
\hline
\end{tabular}

Table 3 ANN fault classification, trained network

\begin{tabular}{|l|ccc|c|}
\hline \multicolumn{1}{|c|}{ Fault } & \multicolumn{3}{c|}{ Outputs } & \% Success \\
\hline no fault & 1 & 2 & 3 & \% Suc \\
line 1 leak & 0 & 0 & 0 & 76 \\
line 2 leak & 1 & 0 & 0 & 91 \\
internal & 0 & 1 & 0 & 85 \\
line 1 + line 2 & 0 & 0 & 1 & 97 \\
line 1 + internal & 1 & 1 & 0 & 96 \\
line 2 + internal & 1 & 0 & 1 & 89 \\
\hline
\end{tabular}

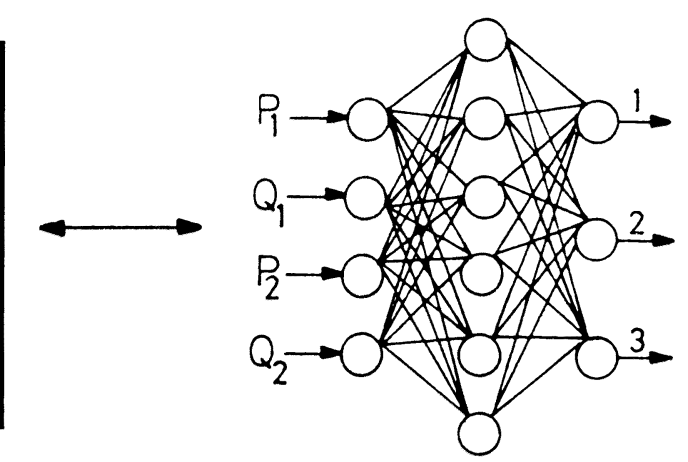

Table 3 indicates the average success over a number of trials. The percentage of correct diagnoses for the single -fault cases is $87 \%$ and $92 \%$ for the multiplefault cases.

\section{THE CO-OPERATING APPROACH - SOME RESULTS}

Single-fault situations present little problem and, following step response stimulation, the displaced volume method is first used with separate diagnoses for extension and retraction. A typical result for line 2 leakage is shown in Fig. 3 where it can be seen that the leaked volumes are only $0.01 \mathrm{~L}$ and $0.02 \mathrm{~L}$ when extending and retracting, and occurring over just 2 seconds. Both steady-state errors have decreased and confirm line 2 leakage as indicated in Table 2 . Running the neural network, following the stimulated open-loop response over full stroke, gave a correct diagnosis percentage score of $99 \%$ for the test data only.

Consider next a multiple-fault case and in particular simultaneous leakage in lines 1 and 2 . The measured data shown in Fig 4 indicates internal leakage from steady-state position errors, but the exact cause cannot be deduced via the expert system rule base. The suggested action is then to "click" the neural network button on the screen which automatically triggers the constant-velocity, full-stroke, open-loop response. The data is then applied to the neural network and the prediction is shown in Fig. 4 , which indicates an $82 \%$ confidence that the multiple fault case is attributable to lines 1 and 2 . 


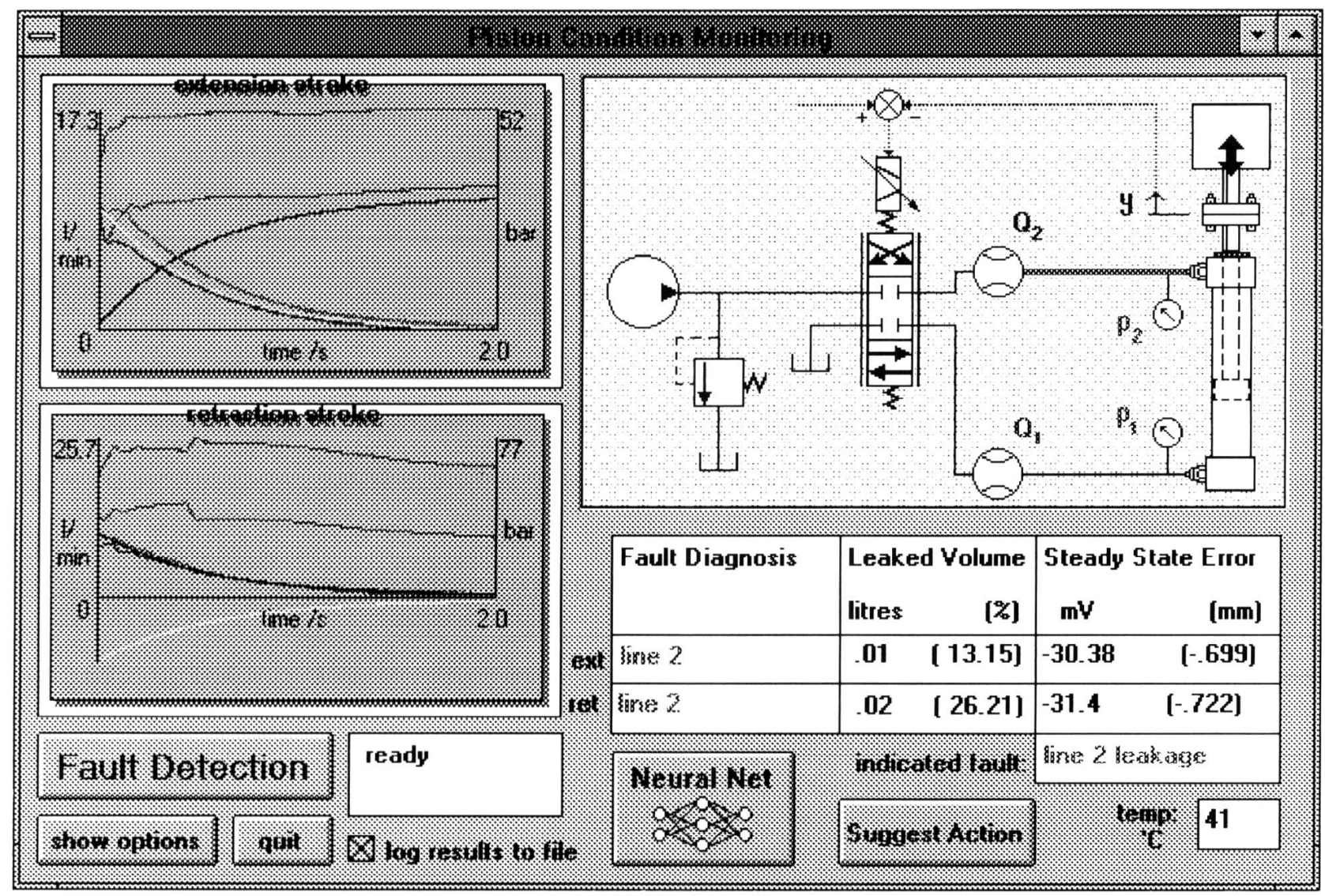

Fig.3 A practical result for line 2 leakage

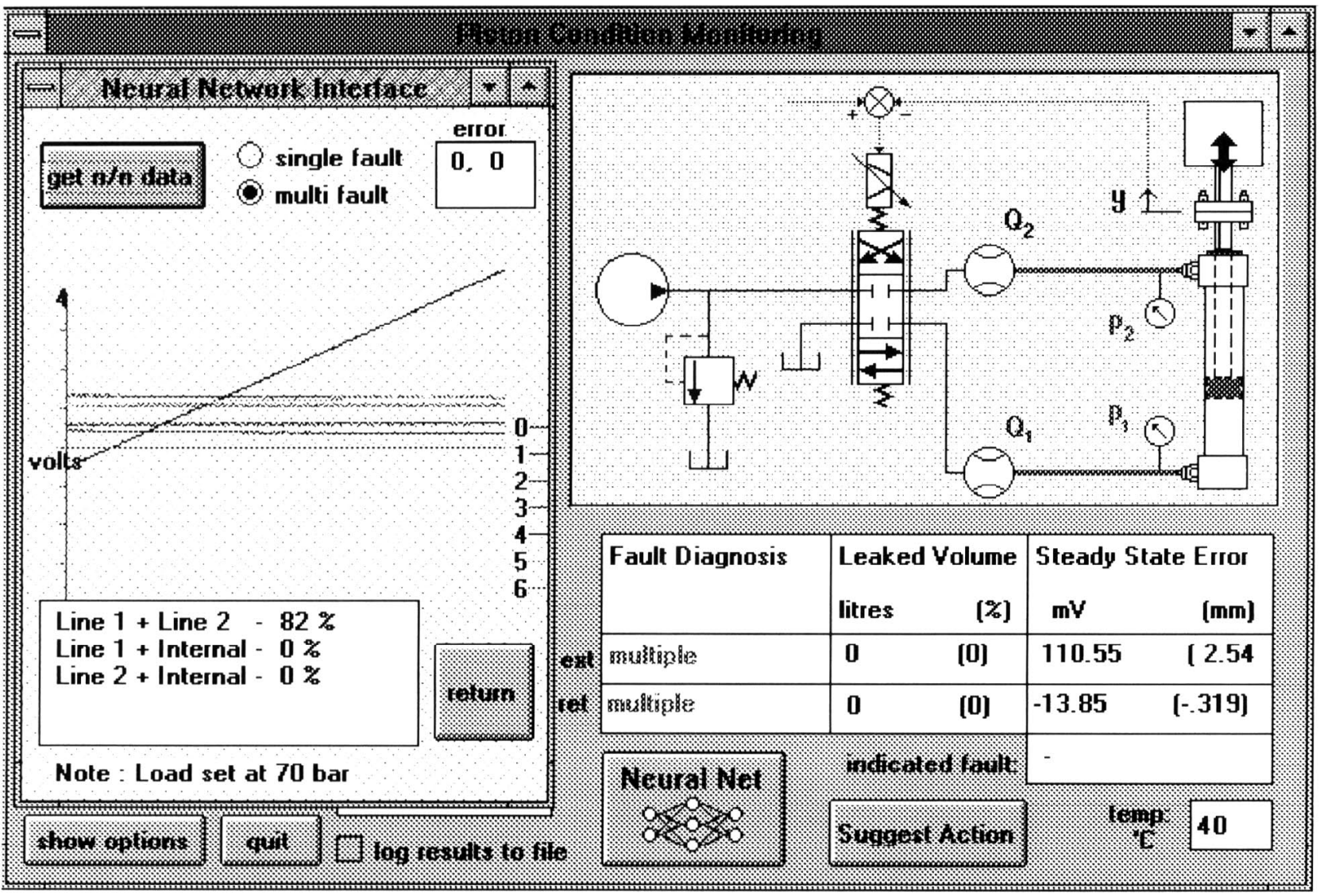

Fig.4 A practical result for multiple faults 


\section{REFERENCES}

1. Creber, D. J. and Watton, J. Development of a Low Cost Expert System Shell for Condition Monitoring of Fluid Power Systems. Proc. 9th International Fluid Power Symposium, Cambridge, 1990, pp.281-291. STI, Oxford.

2. Stewart, J. C. and Watton, J. Fault Diagnosis of a Cylinder Drive using On-line Expert System Techniques. Proc. 10th International Fluid Power Symposium, Brugge, 1993, pp 277-280. Mechanical Engineering Publications Ltd., London.

3. Watton, J., Lucca-Negro, O., and Stewart, J.C. An On-line Approach to fault diagnosis of fluid power cylinder Drive Systems. Proc. IMechE, Journal of Systems and Control Engineering, Vol. 208, 1994, pp.249-262.

4. Atkinson, R. M. et al. Automated Fault Diagnosis for Hydraulic Systems, Part 1: Fundamentals. Proc. IMechE, Journal of Systems and Control Engineering, Vol. 206. 1992, pp. 207-214.

5. Hogan, P.A. et al. Automated Fault Diagnosis for Hydraulic Systems, Part 2: Applications. Proc. IMechE, Journal of Systems and Control Engineering, Vol. 206, 1992, pp.215-224.

6. Bull, D, R. et al. Approaches to Automated FMEA of Hydraulic Systems. Hydraulic Systems Design for the Future Seminar 9, Paper C505/9/099, pp.1-8, Aero Tech '95, Birmingham, UK.

7. Xue, Y. and Watton, J. A Self Organising Neural Network Approach to Data-based Modelling of Fluid Power Systems Dynamics using the GMDH Algorithm. Proc. IMechE, Journal of Systems and Control Engineering, Vol. 209, 1995, pp.229-240.

8. Darling, J. and Tilley, D. G. Progress Towards a General Purpose Technique for the Condition Monitoring of Fluid Power Systems. IMechE Seminar on Aerospace Hydraulics and Systems, London, 1993, pp.47-55.

9. Naylor, J. B. Fault Diagnosis of a Fluid Power System using a Neural Network Approach. M.Sc. Thesis, School of Engineering, University of Wales Cardiff, 1993. 